\title{
African urbanization trends and prospects
}

\author{
Philippe Bocquier \\ Université Catholique de Louvain, Belgium \\ philippe.bocquier@uclouvain.be \\ Andrew Kabulu Mukandila \\ Department of Trade and Industry, South Africa \\ Amukandila@thedti.gov.za
}

\section{Abstract}

The paper aims at analysing and projecting urbanization trends using United Nations, World Urbanization Prospects data, 2007 Revision. A third order polynomial is used to model urban-rural growth difference from 1950 to 2005 country by country. The results of the model are compared to UN projection on urban growth for the period 2010-2050. Using the new model, the African urban population is projected to stagnate around its current level below $40 \%$, with little variations by regions up to 2050 , while the UN predicts $62 \%$. The findings suggest that UN projections are excessively high and do not match the level of economic and social development in Africa.

\section{Introduction}

Urban trends and projections are increasingly used by policy makers not only for urban planning purposes but also by economists and demographers as one of the parameters of long-term economic and population projection models. The UN Population Division provides bi-annual urban projections and these are routinely used by various agencies. However, several authors have questioned their validity against the observed historical urban trends (Cohen, 2004, Bocquier, 2005). National data sources that form the basis of the UN database are criticized, mainly for the data inconsistencies observed in developing countries and for the difficulty associated with the lack of comparable urban definitions (Hugo and Champion, 2003). However, the lack of reliable, timely, and regularly collected data is not the main concern for projections. The UN model has not fit past trends well (National Research Council, 2003, Cohen, 2004), systematically overestimating them because it is based on the assumption of convergent transition to high level urbanization and on the use of an incorrect assumption of linearity of the transition process (Bocquier 2005). Conforming to the mobility transition theory (Zelinsky, 197I), an alternative method has proved more effective in projecting urban trends at country level (Bocquier, 2005).

This paper explores urban trends and projections obtained for Africa in comparison with other regions of the developing world, using a variant of the alternative method of projections (Mukandila, 20I0) on recent UN data (United Nations, 2009). We will systematically compare our projections for Africa with those of the UN at country 
level as well as sub-regional level. Results for Africa will be compared to those for other parts of the developed and developing world. Projections and their comparison are expected to help African policy makers to adjust and give priorities to urban or rural service delivery depending on the anticipated increase in urban population.

\section{Literature review}

The United Nations Population Division provides the most comprehensive and widely used urban estimates and projections at national level. UN generates data on urbanization by interpolation (starting from Ist July 1950 to the end estimation period, I st July 2005) using available census or survey data. UN then extrapolate urban trends from 2005 to 2050 based on a linear regression model projection. The inter-period Urban-Rural Growth Difference, denoted rur at time $t+I$ in UN documents is the difference between urban growth and rural growth:

$$
\text { rur } t \quad 1 \quad u t \quad 1 \quad r r t
$$

where $u(t+I)$ and $r(t+I)$ are respectively urban and rural growth rates in the interval of time $[t, t+\mathrm{I}[$ and are derived respectively from urban and rural population at the time between time $t$ and time $t+\mathrm{I}$.

The proportion urban (PU) is the fraction of the total population living in urban areas at a given time, expressed as percentage of the total. It can be derived at any time $T$ between two censuses from urban-rural ratio as follow:

$$
P U(T) \frac{U R R(T)}{1 U R R(T)}
$$

where $U R R(T)$ is the urban-rural ratio resulting from dividing the urban population by the rural population. It can be expressed as a function of $\operatorname{rur}(t+n)$ :

$$
U R R(T) \quad U R R_{t} * e^{\operatorname{rur}(t \quad n)^{*}(T \quad t)}
$$

The UN regression model used for projection is a weighted average of prior estimation of rur and hypothetical urban-rural growth difference noted hrur. This hrur is computed from a regression model of rur against $P U$ for countries of 2 million inhabitants or more:

$$
\begin{array}{llll}
\operatorname{rur}(i, t \quad 5) & W_{1, t} * \operatorname{rur}(i, t) & W_{2, t} * \text { hrur } & \\
& W_{1, t} * \operatorname{rur}(i, t) & W_{2, t} *( & * P U(i, t))
\end{array}
$$




$\begin{array}{lllllll} & W_{1, t} & 0.8 & W_{2, t} & 0.2 & \text { when } t & 2005 \\ \text { Where } & W_{1, t} & 0.6 & W_{2, t} & 0.4 & \text { when } t & 2010 \\ & W_{1, t} & 0.4 & W_{2, t} & 0.6 & \text { when } t & 2015 \\ & W_{1, t} & 0.2 & W_{2, t} & 0.8 & \text { when } t & 2020 \\ W_{1, t} & 0 & W_{2, t} & 1 & \text { when } t & 2025\end{array}$

National Research Council (2003), Cohen (2004) and Bocquier (2005) are among those who have criticized UN projection model because of its implicit assumption that all countries will follow the historical path processes of urbanization experienced by developed countries. It is regrettable that UN model and projections have not attracted more critical attention from users and demographers. Literature reviews on urbanization that are otherwise well documented appear to take UN projections as granted, which is expected when these documents are produced by UN agencies (UN-Habitat, 2008, UN-Habitat, 2007, UNFPA, 2007) but less so when they come from independent bodies or scientists (Worldwatch Institute, 2007, Satterthwaite, 2007, O'Neill and Scherbov, 2006, Kessides, 2005).

Cohen (2004) was the first to investigate the quality of the available data, and the uncertainty of UN urban projection. Though he considered the data provided by the UN World Urbanization Prospects as invaluable and comprehensive resource on urban population change, the findings suggest lack of accuracy in past urban projections. The paper criticizes the $U N$ assumption that urbanization in developing countries will continue more or less unchecked and that large agglomerations will continue to grow to extraor- dinary height into the future as source of projection errors. Cohen (2004) distinguished trends in large cities, intermediate and smaller cities in developing countries. He suggested that large cities will play a significant role in absorbing anticipated future growth but the majority of residents still reside in much smaller urban settlements. Contrary to the popular view, he suggested that by 2015 , the proportion of the world's population living in large cities (having a population of one million or more) will approximate only $21 \%$. Only $4.1 \%$ of the world's population would be living in "mega-cities" (having 10 million or more inhabitants). In other words, Cohen suggested that most urban growth over the next 25 years will occur in far smaller cities and towns.

The UN methodology assumes that all countries will follow in their urban transition the pattern of developed countries and reach the same level of urbanization over time. But empirical evidence shows that the urban transition follows different patterns according to the historical period each country went through and to its level of economic development. The curve formed by plotting URGD against PU shows different shapes, although most of them are indeed inverted U-curve. Graphically, it means that the plot of the urban-rural growth difference (URGD) against the proportion urban (PU) 
should form an inverted U-curve, starting at $0 \%$ or so and finishing at a maximum of $100 \%$. At the end of the mobility transition, the proportion urban should saturate and urban growth declines to zero. This conforms to the mobility transition theory (Zelinsky 197I) that recognised that each country might follow the urban transition at its own pace. This seems to be indeed the case, as some western countries took more than two centuries to reach their current level of urbanisation whereas some other countries experienced the same transition in less than 50 years. However, we should be careful in taking a narrow evolutionist perspective on urbanization. The simplistic version of the evolutionist perspective, which considers past societies as rural and immobile, has been questioned (Skeldon, 1997). Historical inaccuracies, especially regarding the assumed low and inconsequential mobility of ancient or developing societies, have been identified (Lucassen and Lucassen, 2009). For his defense, it should be reminded that Zelinsky was careful to say that the progression through phases was indicated for an "ideal nation" (Zelinsky 197I:23I). The urban transition like any other evolutionary process is not linear. Zelinsky actually insisted that the process is gradual in space and time, starting from a growth pole (broadly speaking, Europe) and extending to peripheral areas through the spatial extension of the capitalist mode of production and, in particular, colonization. Not all countries should go through all phases in the same way as in the growth pole. Zelinsky is particularly concerned with countries that failed to progress in phases of demographic and urban transitions and he had difficulty admitting that the universality of the transition should not necessarily mean that transition is ending the same everywhere (Zelinsky 1971:242).

However, Zelinsky clearly stated that the transition modalities depend on the moment the transition started (Zelinsky 1971:249). The urban transition in Africa started when the transition was well under way in Europe and even in other continents. This heterogeneity in transition does not mean that the transition obeys different laws in different parts of the world, but that the experience of early transitions is used so that late transitions occur faster. It took two or three hundred years for European countries to reach their current stage in the transition, while it took less than half a century for others. This is well illustrated by the varying speed at which vital transitions (Reher, 20II) and urban transitions (Dyson, 20II) happened in developed and developing countries.

Bocquier (2005) investigated the acceleration and deceleration stages of urban rural growth difference over the urban transition period. He compared developed and developing countries' URGD (denoted rur in UN reports) plotted against $P U$ to measure the stage of transition. The projections improve when the difference of growth between urban and rural areas is measured in absolute terms rather than in relative terms. Instead of modelling rur, it is better to model the excess increase in urban areas, denoted $x u$ : 


$$
x u_{t} \quad U_{t} \quad U_{t 1} \quad \frac{U_{t} R_{t}}{U_{t 1} R_{t 1}} \quad U_{t} \quad U_{t 1} .\left(1 \quad p_{t}\right)
$$

where $P_{t}$ is the total population growth rate and $U_{t-1} \cdot\left(I+P_{t}\right)$ is the hypothetical absolute increase in urban areas if the urban areas were to grow at the same

$$
x u_{t} \quad \operatorname{rur}_{t} \frac{U_{t 1} R_{t 1}}{U_{t 1} R_{t 1}}
$$

The main reason for preferring $x u$ over rur is its ability to control for population growth. Contrary to rur, which expresses a difference between growth rates, $x u$ depends not only on this differential but also on the total population growth. When the total population grows less, the number of migrants from the sending area is also diminishing, thus reducing the potential growth of the receiving area. The use of $x u$ can also be interpreted as a control of the rate as the total population. Bocquier demonstrated that $x u$ has a close relation to rur:

capacity of the urban areas to absorb an excess increase in absolute terms. Urban infrastructures capacities grow at a slower rate than the population. This limit to urban growth is not captured by the rur. The projection using $x u$ will then be constrained by the overall population growth and therefore be dependent on, but also sensitive to, the projection of the total population.

Therefore, the following relation can be established...

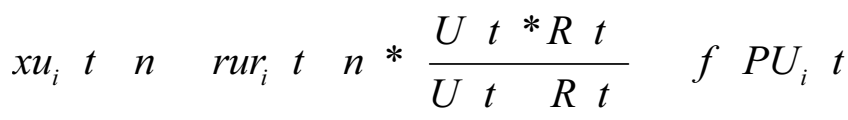

...and is adjusted by a polynomial of second degree:

$\begin{array}{llll}x u_{i} t & n & f\left(P U_{i} t\right) & { }_{i, 0} \quad{ }_{i, 1}^{*} P U_{i} t \quad{ }_{i, 2}^{*} P U_{i}^{2} t\end{array}$

with:

i: Region or country

$t$ : the year (time) of reference

$P U_{i}(t)$ : Percentage of population that is urban (Percentage Urban)

$n$ : n-year increment for step by step projection.

${ }_{i, 0},{ }_{i, 1}$ and ${ }_{i, 2}$ : Parameters computed for $i$, based on historical trends

The equation (7) models the excess in urban areas in the country $i$ at the time $t$ given the relation (6). It is understood that $\operatorname{rur}_{i}(t+n)$ depends only on urban-rural growth differential while 
$x u_{i, t+n}$ depends not only on this differential but also on the total population growth of the country $i$ expressing the ability to control for the population growth (Bocquier, 2005). Contrary to the UN assumption, Bocquier methodology suggests that each country will follow its own pattern of urban transition at its own pace and achieving its own level of urbanization. The speed of urban growth differs from country to country and is related to the economic position of the country in the world. In the Figure I, if $\beta_{1}$ and $\beta_{2}$ are speed of urbanization respectively acceleration and deceleration and $a, b$ and $c$ respectively least developed, developing and developed countries. The model assumes that countries have different speed of urbanization expressed by $\beta_{1}^{a}>\beta_{1}^{b}>\beta_{1}^{c}$ leading to different level of urbanization $\mathrm{PU}^{a}>\mathrm{PU} \mathrm{U}^{\mathrm{b}}>\mathrm{PU}$.

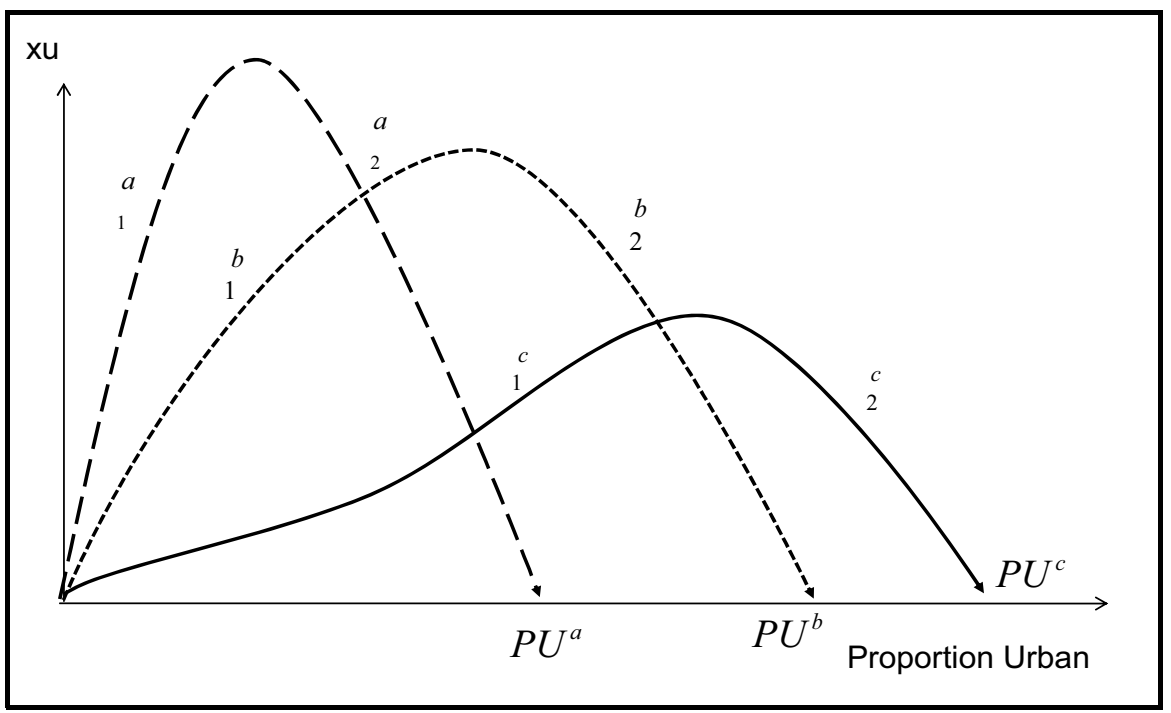

Figure I Ideal-type of xu-PU relationship for various level of development

The proportion urban at which the URGD seems to converge to zero (called urban saturation point for convenience, when rural and urban areas are growing at the same pace) is different from one country to another and possibly corresponds to the urban capacity of the economy. The final stage of the transition depends on the country's position in the global system and defines when urban area is saturated.

In sum, the Bocquier model takes into account two factors: the speed of urban transition and possible urban saturation. The model relies belongs to the class of autoregressive, endogenous models, as the UN projection model. In other words, it does not use exogenous variables (such as GDP, HDI, etc.) to explain the proportion urban and its trend. Unlike the UN model, the Bocquier model does not impose convergence toward an average behaviour. Instead each country follows its own urban transition, leading to different level of urban saturation.

However, the Bocquier model cannot describe and adjust all historical trends. It assumes that the parameter $\beta_{0}$ should be close to zero for all coun- 
tries, although no constraint was imposed to that effect. Also, the model does not easily cater for highly unstable urban transitions as later exemplified with South Africa. In other words, in both UN's linear and Bocquier's curvilinear models urban transition is assumed to be stable, which might not be realistic in all historical situations.

\section{Method and limitations}

In the present paper, we explore a variation of the Bocquier model to analyse urban transition in Africa, in comparison to the rest of the world. Our model will also rely on UN urbanization series only. UN urban and rural population data used in this paper are those published in the World Urbanization Prospects (WUP 2010) using country results that are derived from census, country estimate, register of population, sample survey or UN estimate. The UN is then interpolating data at fixed dates starting from 1950 with 5-year increment up to 2005.Ideally, we would prefer to model the original data as provided by each country for the period 1950 to 2005 , then project for the period 2010 to

$$
y_{i} \quad{ }_{i, 0}{ }_{j 1}^{k} \quad i, j x^{j} \quad i
$$

where $y$ is the observed value (rur) for the model, $x$ the proportion urban, $\beta_{1}, \beta_{2}, \beta_{3}, \ldots, \beta_{k}$ coefficients for $j$ th power of the predictor $(j=1,2 \ldots k), \beta_{0}$ is the intercept of $Y$, a constant which is preferably equalled to zero, and $\varepsilon$ is the error term.

The values of parameters will be determined by values that minimize the sum of the squares of distances between data points and fitted curve.
2050. However, empirical data are not usually available to the public for most countries. We are therefore relying on UN estimate to compensate for the shortage of empirical data mostly in developing countries, and also to ease comparison with UN results.

Our analysis will focus on two variables, namely country population and urban population, for any individual country. The two variables are repeated measures across countries and time, forming a cross-sectional 5year time-series that can be analysed as panel data. A variable named excess urban increase will be created to model growth over time of the each country (see previous section). Bocquier (2005) projected urban growth using the polynomial of second order. In the present paper, we are using a polynomial equation of third order with constant term equalled to 0 , which conforms better to the theoretical shape of the urban transition, as exemplified in Figure I. The regression will be based on the following polynomial equation relative to the observed data:

The intercept $\beta_{0}$, will be constrained to equal zero for all countries. Considering that we are only considering data from 1950, well after the urban transition in most countries, this hypothesis is inconsequential but reflects that urbanization should in principle start from $0 \%$ urban population. Replacing $x$ by $P U(t)$, $t$ being an index of time, we will model urban growth using a polynomial of third degree for country $i$ : 
$f P U_{i} t \quad * P U_{i} t \quad{ }_{i, 2} * P U_{i}^{2} t$
The research will exploit the maximum likelihood random effect model to model the trend, but no attempt is made to use the goodness of fit or standard errors to project the trend or to give confidence interval of the trend. As the data are not real panel data but interpolated data at fixed time interval, the goodness of fit and standard errors would not be reliable. The model is implemented with the command ' $x$ treg' and options 'mle noconstant i(country)' in Stata.

Despite the constraint imposed on the intercept, the third order polynomial model suffers from the same limitations as the second order polynomial model in its capacity to adjust unusual historical trends. According to the theory, Urban-Rural Growth Difference should follow an inverted-U shape when plotted against the proportion of the population who live in urban area (PU) over the urban transition period. However some countries do not follow this pattern. The historical inverted- $U$ shape will be affected by country specific (idiosyncratic) historical trend. For example, South Africa's inconsistency in urban trend can find its explanation in the apartheid history where people had no free movement from rural and urban areas, at a time when the economy was declining due to international trade restrictions. China's urban trend is another example of a country where people were forced to live in rural areas (Cultural Revolution in China). When the policy restricting people to live in rural areas is lifted up a rebound is generally observed in the urban trend.

The limitation is not restricted to idiosyncratic historical trend. It also applies to change in urban definition that may have led to inconsistent urban
* $P U_{i}^{3} t \quad{ }_{i}$

trends. Although the UN Population Division tries its best to correct past trends using updated definition, we cannot exclude some remaining inconsistencies are changes in definition are not always documented, let alone consistent implementation in national reports. It is virtually impossible to identify for all countries of the world and even of Africa all the changes and the way they were implemented over the last 60 years. Cases in the Results section illustrate some of the historical or data limitations found in some African countries only. Whatever the underlying reason for inconsistency, trends that do not approximate the expected inverted- $U$ curve will be dealt with in one of the following two ways:

I. Discard the early part of the series that has abnormal trends and use the rest (truncated series): the model will only take into account the period where there is consistency (bell shape) in URGD trend.

2. If all the series cannot be used (often the case with poor quality of the original data), the country will be discarded.

A table of countries indicating the period affected by corrections is provided in Appendix I. Five countries had to be discarded, of which four are in Western Africa: Eritrea, Burkina Faso, Côte d'lvoire, Mali and Nigeria. Needless to say that discarding Nigeria, the most populated country in Africa is a serious limitation to our projections for Africa as a whole. Also, among the other 56 countries or territories that were eventually adjusted, the early part of the series of 28 (exactly half of them) was truncated. 
Results: comparison of historical and fitted trends

The period between 1950 and 2005 was adjusted and the goodness of fit was evaluated by observing the trend of excess urban population $(x u)$ against percentage urban $(P U)$ and four classes describe the reliability of the model on each country's data (see Annex). The classes (good, average, poor and unacceptable) are based on the reliability of the fit of the $3^{\text {rd }}$ order polynomial model.The trends of $x u$-PUby country were categorised into three urban transition stages, namely early, mid and late transitions.

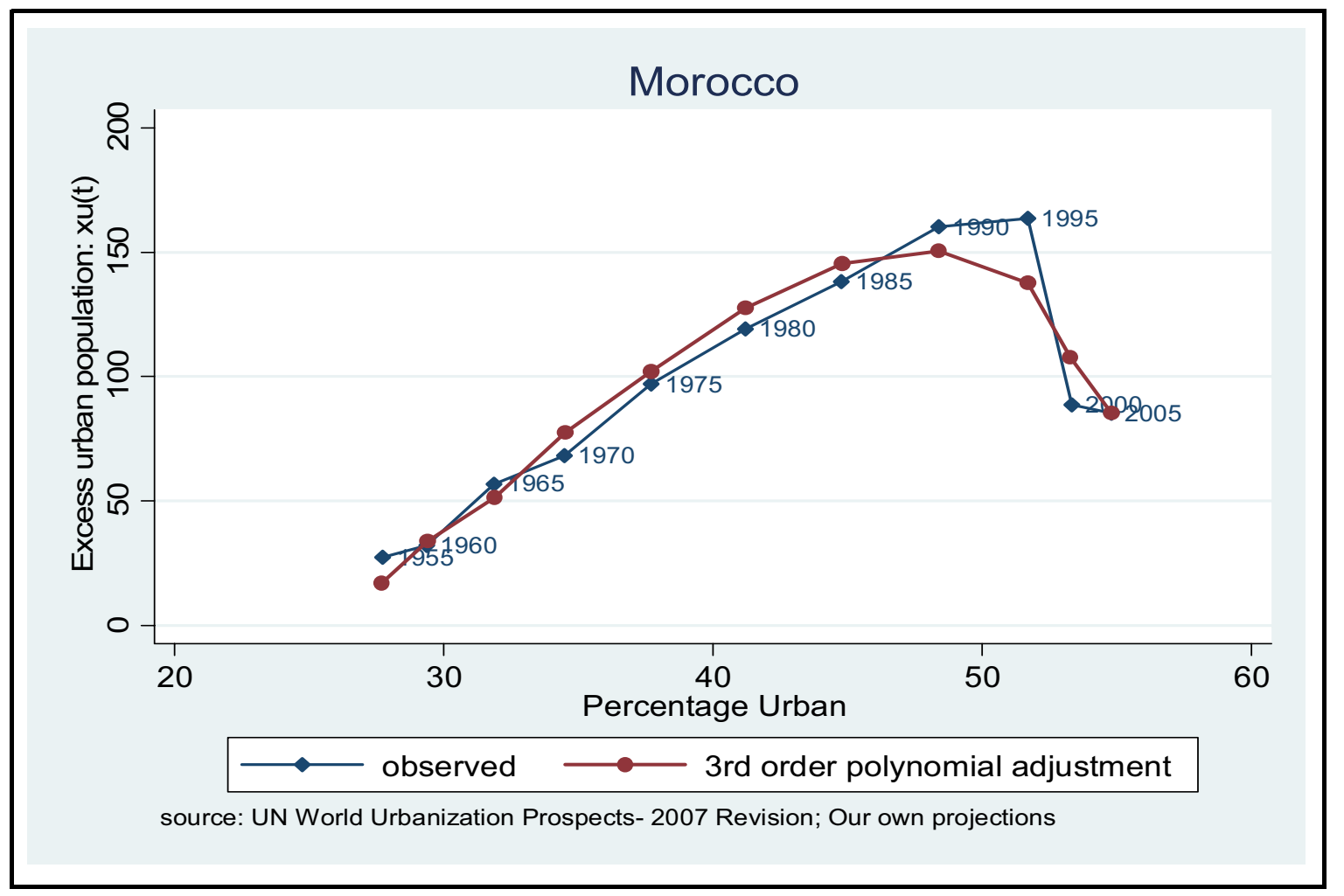

Figure 2 Excess urban population vs. Percentage urban: observed and adjusted trends for Morocco (good fit and mid-stage transition)

Figure 2 to figure 6 present the adjusted and observed xu-PU trends for five typical countries. Morocco represents countries with a good fit, at mid-stage in the urban transition. The figure indicates that excess urban population in Morocco has already reached its maximum and has just started to decrease towards zero. Kenya's figure is an example of mid-stage transition. The excess urban population decreases rapidly since 1985 while the percentage urban growth slow down significantly. Zambia reached its late-stage of transition since 1985. The figure suggests that the urban growth become stationary since 1985 and also reverse move is depicted form the figure. The reversal in urban growth needs to be investigated to determine if it is due to bad data on urban population, change of urban definition or real high growth in rural areas exceeding urban growth. 


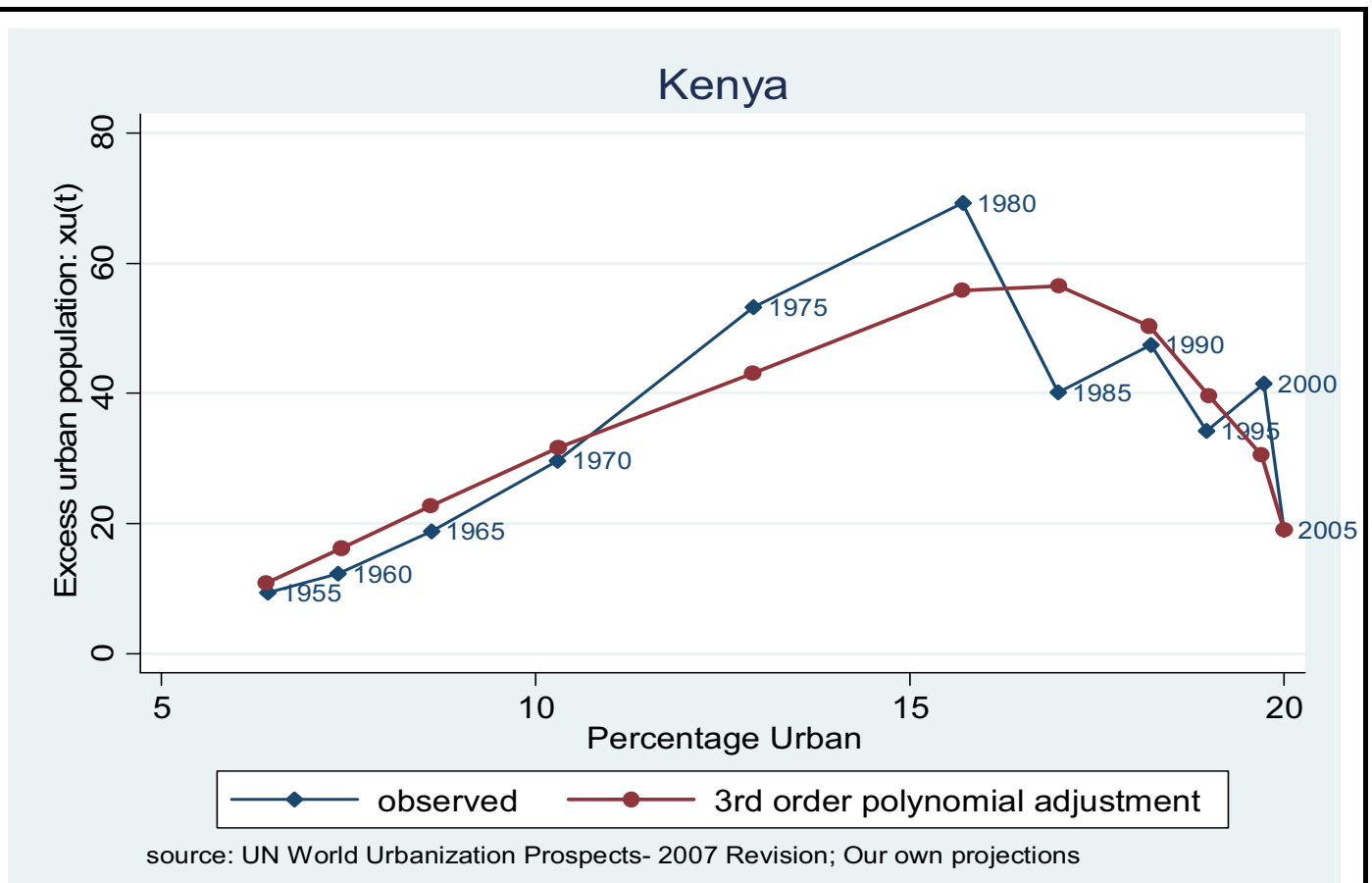

Figure 3 Excess urban population vs. Percentage urban: observed and adjusted trendsfor Kenya (average fit and mid-stage transition)

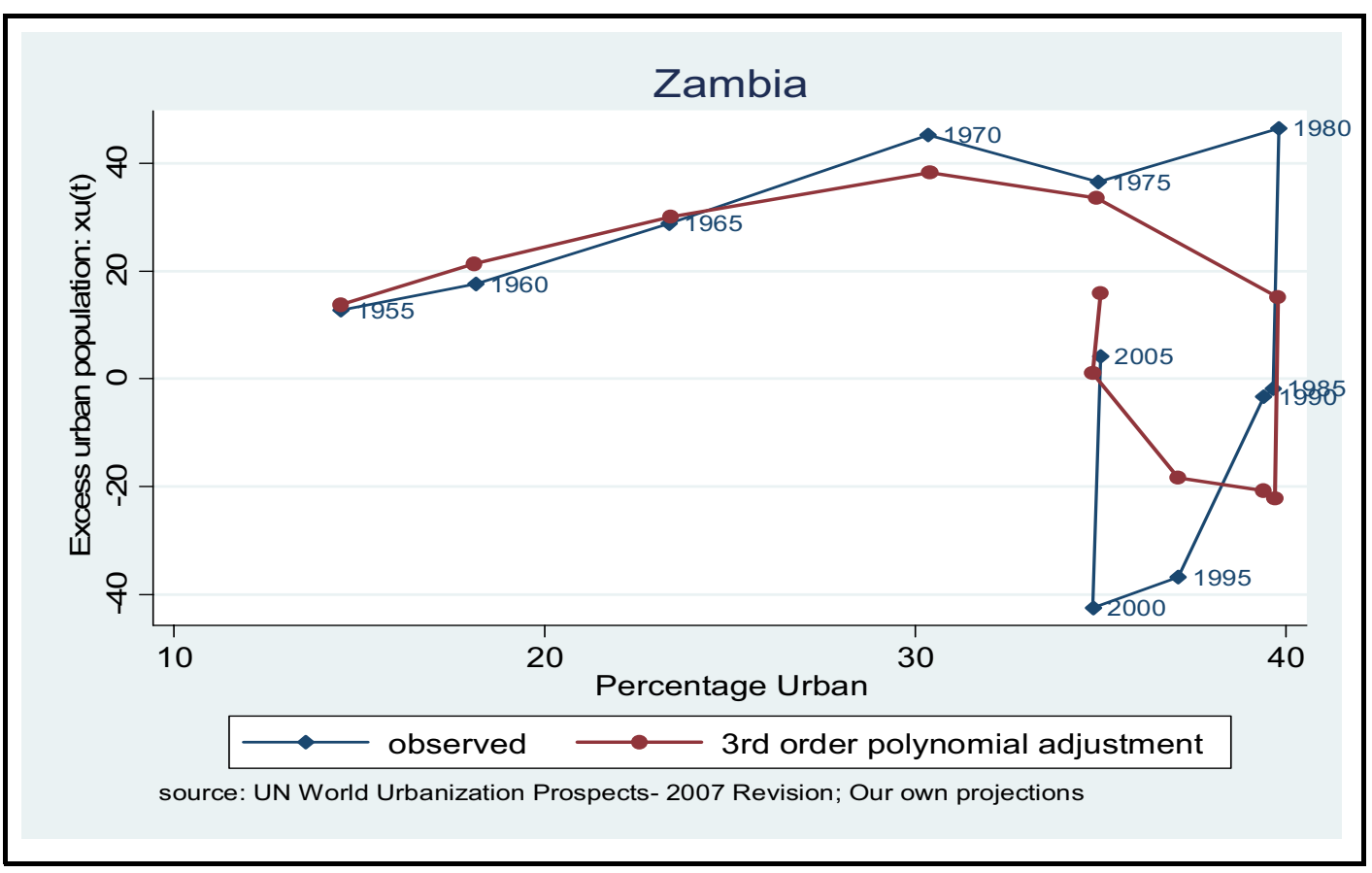

Figure 4 Excess urban population vs. Percentage urban: observed and adjusted trendsfor Zambia (average fit and late-stage transition) 


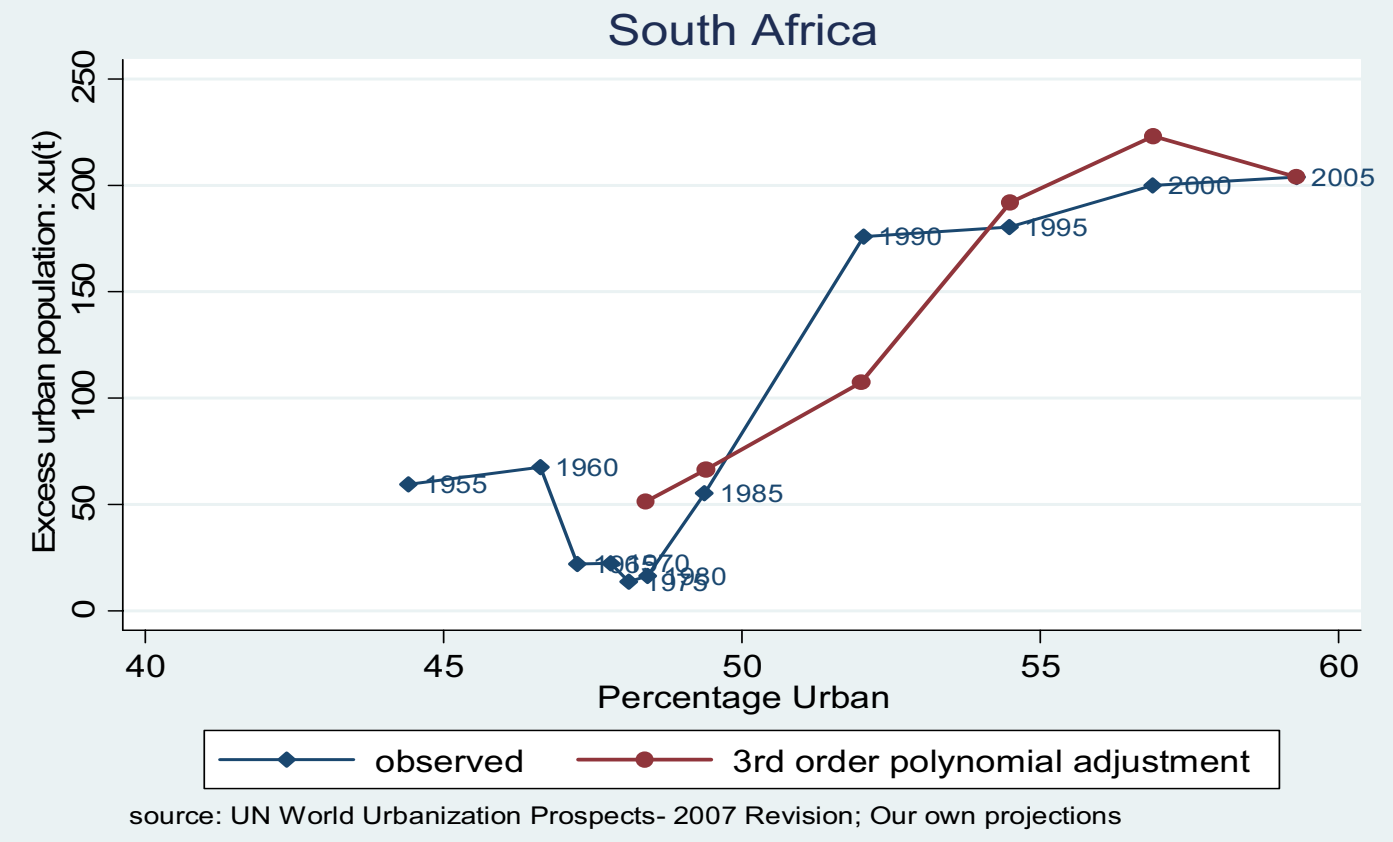

Figure 5 Excess urban population vs. Percentage urban: observed and adjusted trendsfor South Africa (poor fit and mid-stage transition)

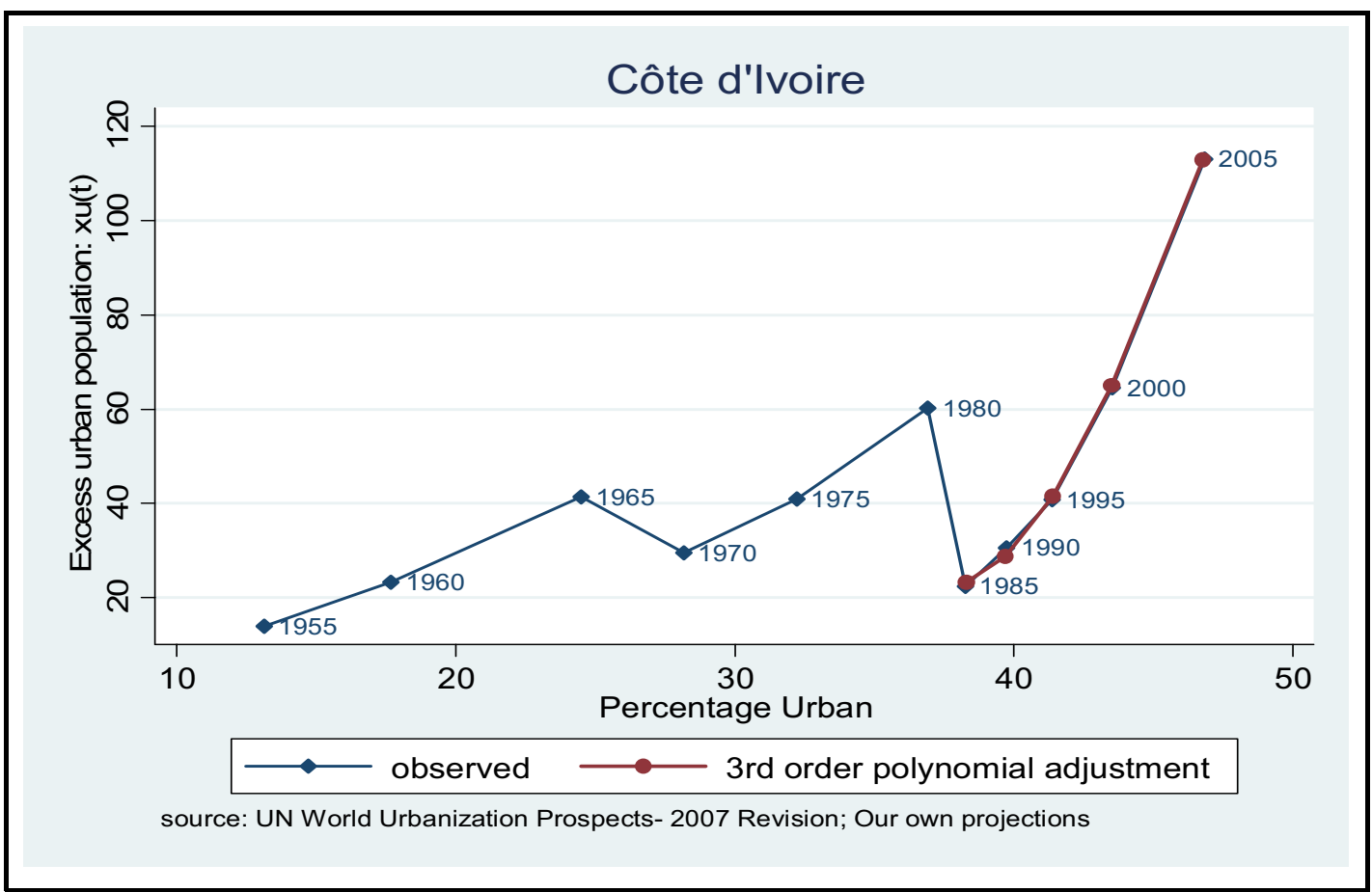

Figure 6 Excess urban population vs. Percentage urban: observed and adjusted trendsfor Côte d'Ivoire (unacceptable fit) 
Urban population growth in South Africa did not follow a trend consistent with the theory of urbanization. The situation in 1980 (when urbanisation virtually stopped) can be linked to the apartheid era and its laws imposing population to remain in homeland. When these laws were abolished (gradually in the early 1980s), a rebound of excess urban population was observed, followed by a rapid urban population growth until the process reached its peak in the years 2000 s. The projection on South Africa using the period between 1980 and 2005 suggests that urban growth will continue albeit slowly until reaching $61.6 \%$ of the total population living in urban areas.

The figure for Côte d'lvoire is an indication that the historical data on urban population is not consistent with the urban transition model.The series shows that the proportion urban would keep growing and eventually reaching
$100 \%$. For lack of detailed information, it is difficult to say if this situation is due to faulty data, to change of definition or to the political and economic turmoil as the country experienced both a civil war and an economic recession. This is a good illustration of the limitations of the model to account for blatant inconsistencies in the historical series.

The following figures represent the urban-rural growth difference (URGD) against the percentage urban $(P U)$ for a selection of other African countries. They show clearly that the URGD projected by the UN departs greatly from the curvilinear historical trends. Even with relatively poor fit, our projected trends follow better the observed trends. To note, our model fits reasonably well trends that lead to saturation, when the proportion urban hovers around a convergence point as in Mauritania or Niger.

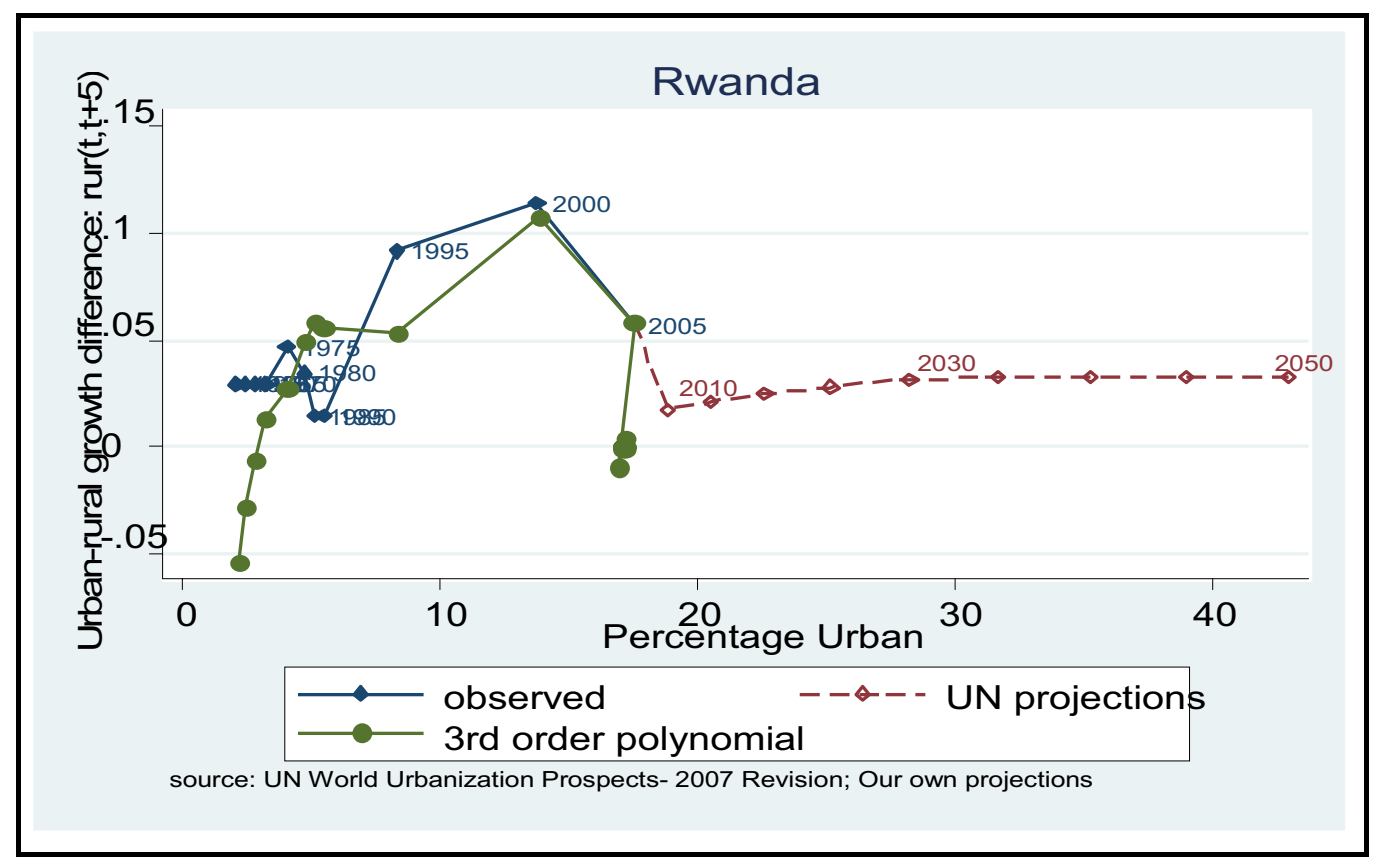

Figure 7 Urban-rural growth difference vs. Percentage urban: observed, adjusted, and projected trendsfor Rwanda (poor fit and mid-stage transition) 


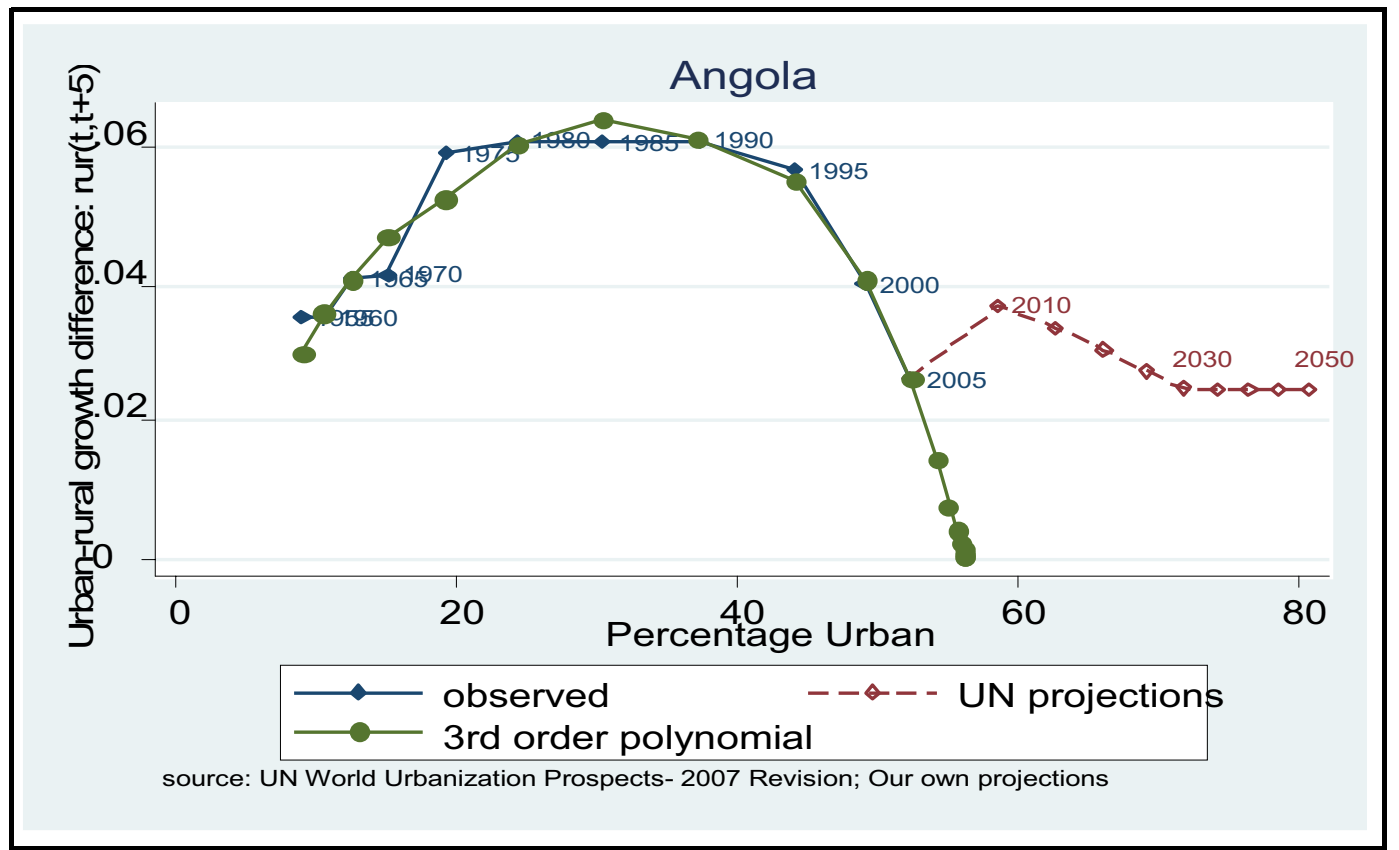

Figure 8 Urban-rural growth difference vs. Percentage urban: observed, adjusted, and projected trendsfor Angola (good fit and mid-stage transition)

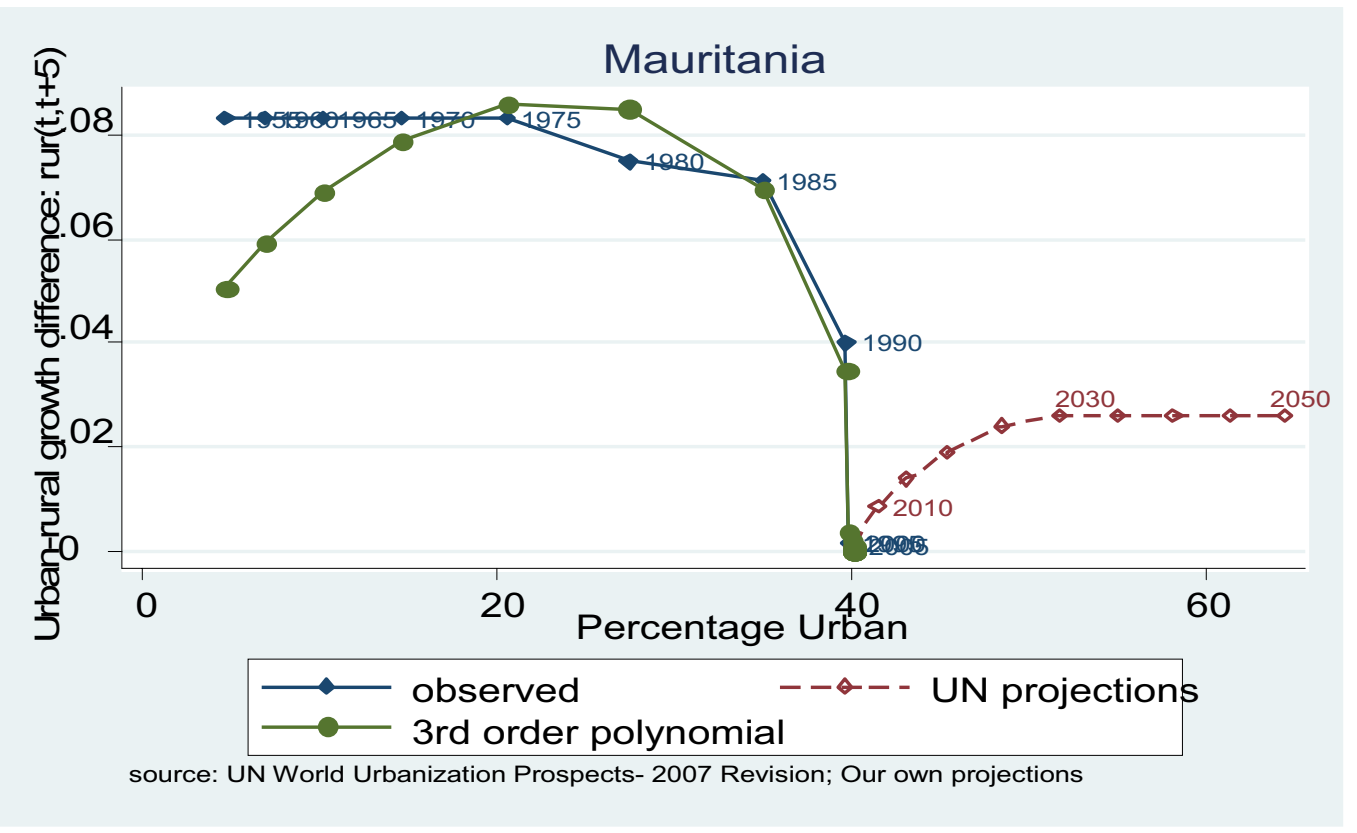

Figure 9 Urban-rural growth difference vs. Percentage urban: observed, adjusted, and projected trendsfor Mauritania (good fit and late-stage transition) 


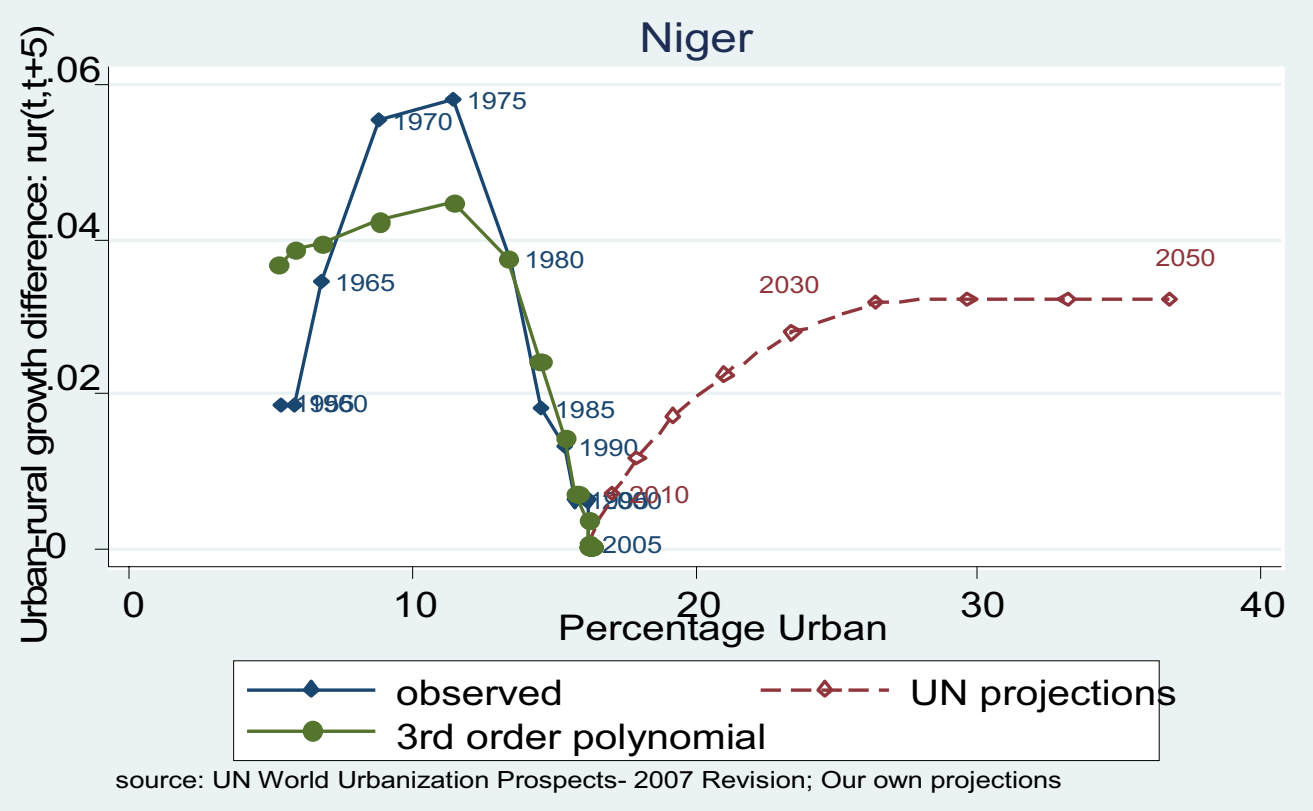

Figure 10 Urban-rural growth difference vs. Percentage urban: observed, adjusted, and projected trendsfor Niger (poor fit and mid-stage transition)

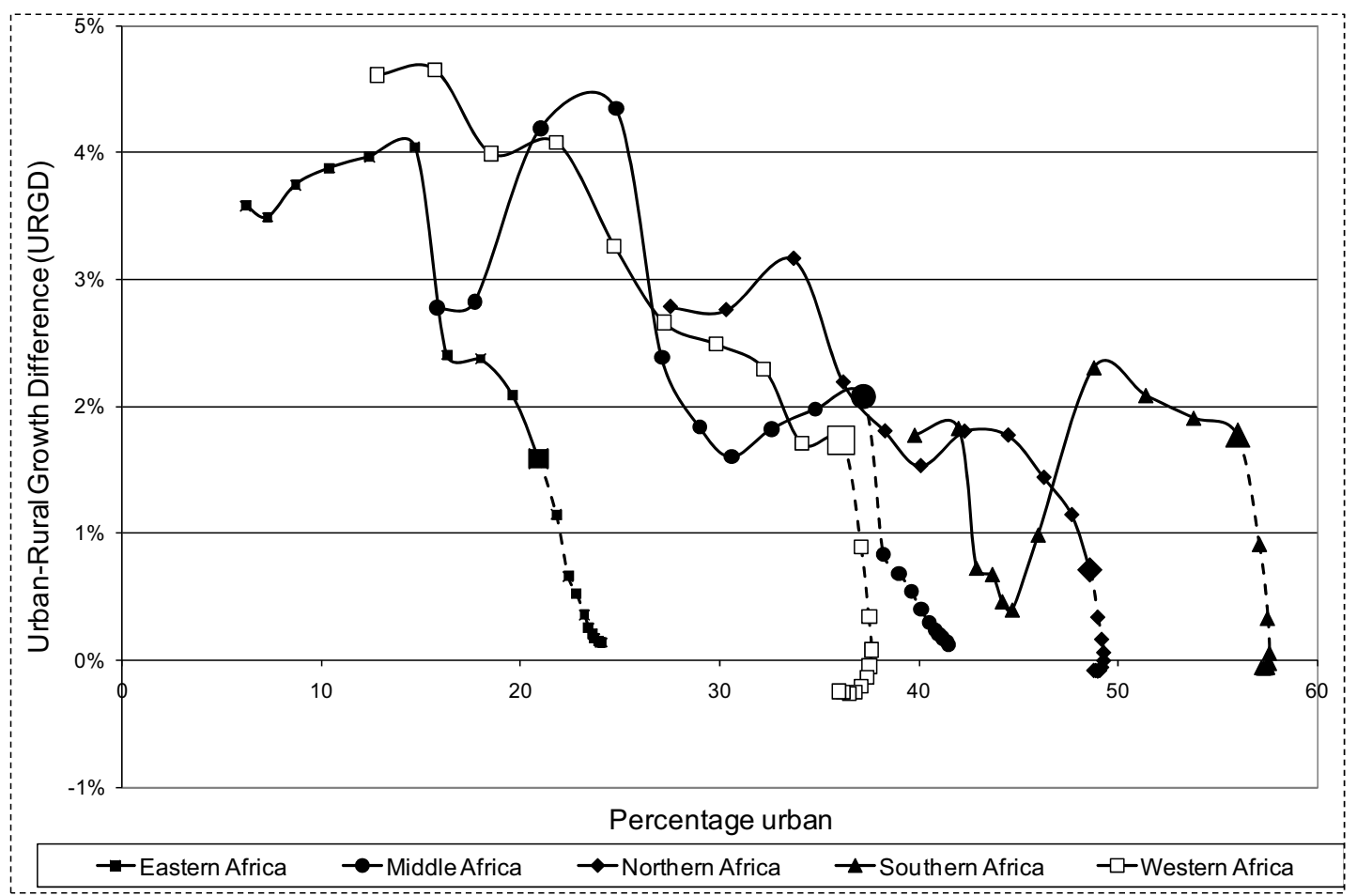

Figure I I Urban-rural growth difference vs. Percentage urban: observed (plain line 1955-2000) and projected trends (dotted line 2000-2050) for the five African sub-regions (Western Africa without Burkina Faso, Côte d'Ivoire, Mali and Nigeria; Eastern Africa without Eritrea) 
The aggregated URGD trends (historical and projected) show that urbanisation converges to fairly low level for all regions of Africa (Figure II). Because trends for some countries could not be fitted well with our model, these countries were removed from the aggregates. This is particularly crucial in Western Africa where data on Nigeria, the largest country on the continent, had to be removed, as well as Burkina Faso, Côte d'Ivoire, and Mali. The estimates for Western Africa are therefore very tentative. Finally Figure 12 depicts URGD trends for several developing sub-regions of the world. Africa and Asia (without China) form a specific group that departs from American subregions.

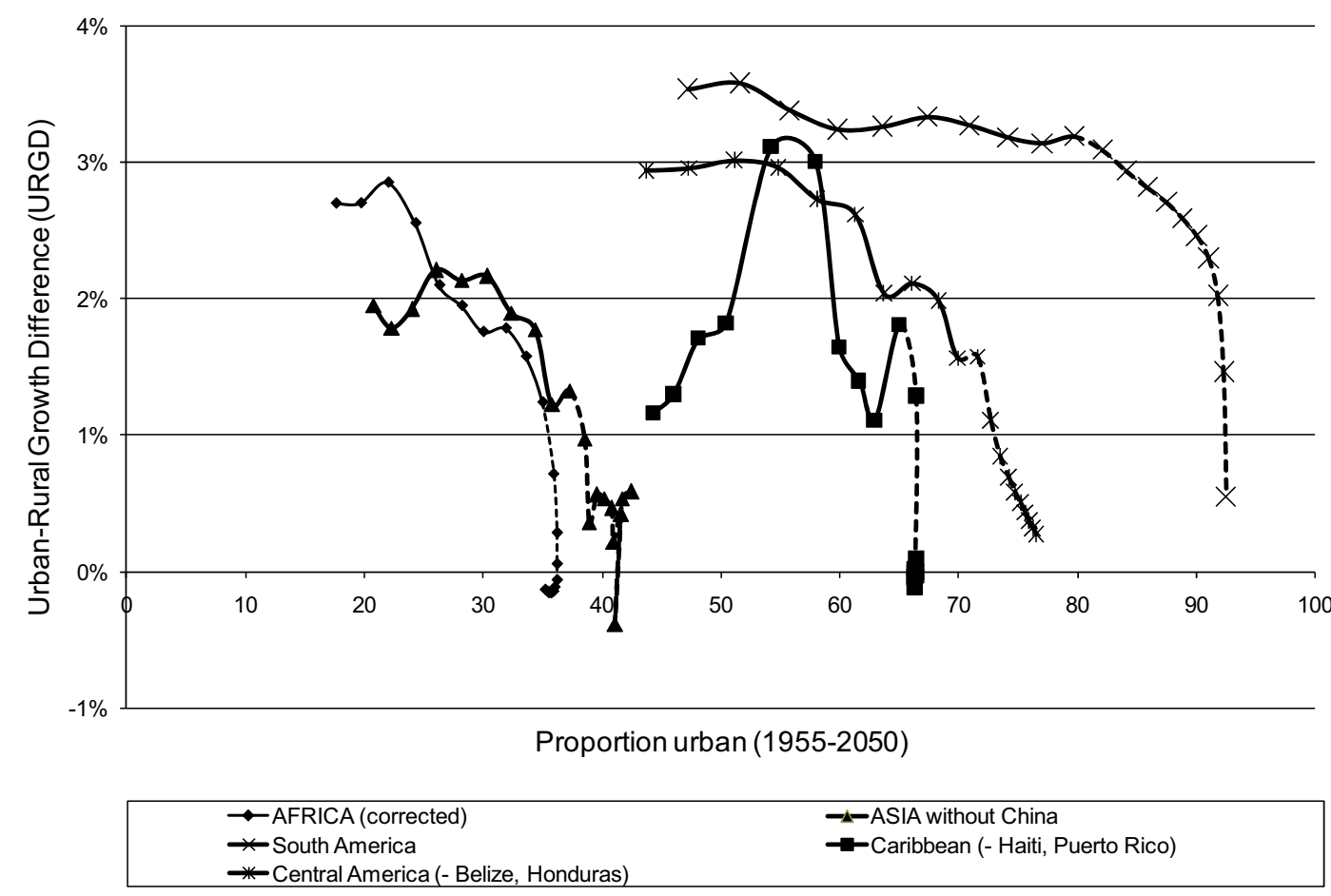

Figure 12 Urban-rural growth difference vs. Percentage urban: observed (plain line 19552000) and projected trends (dotted line 2000-2050) for Africa (without Burkina Faso, Côte d'Ivoire, Mali, Nigeria, Eritrea) and Latin America (without Haiti, Puerto Rico, Belize, and Honduras)

\section{Discussion: urbanization trends and projections}

In this section, we will first discuss the African urbanization trends for the period 1950-2005, then discuss the projections for the period 2005-2050, and finally compare African trends and projections with those of other devel- oping sub-regions.

As shown in Figure 13, in all subregions of Africa, the percentage urban increased by at least 20 percentage points from 1950 to 2005, except in Eastern Africa (16.5 points). As compared to 1950, the ranking in 2005 remained the same with Southern 
Africa being the most urbanized (beyond $55 \%$ ), followed by Northern Africa (close to 50\%), and Eastern Africa the least (barely above 20\%). The trend in Southern Africa is very much influenced by South Africa and that explains the apparent stall in the 1970s and the rebound in the late 1980s corresponding to the end of Apartheid. Urbanization in Middle Africa and Western Africa is comparable (between $35 \%$ and $40 \%$ ) and close to the African average. Although we did not include Nigeria, Burkina Faso, Côte
d'Ivoire, and Mali (see previous section) in the figures, the trends for Western Africa and Middle Africa would not be very different and maybe lower. It is often believed that Nigeria is more urbanized than other Western African countries, but recent research has proved otherwise (Potts, 2012). The percentage urban was estimated at $36 \%$ by the 199 I Census and at $42.5 \%$ in 2000 by the UN, while Africapolis Team (20II) evaluates only at $30 \%$ the percentage living in agglomerations of 10,000 people or morein 2000.

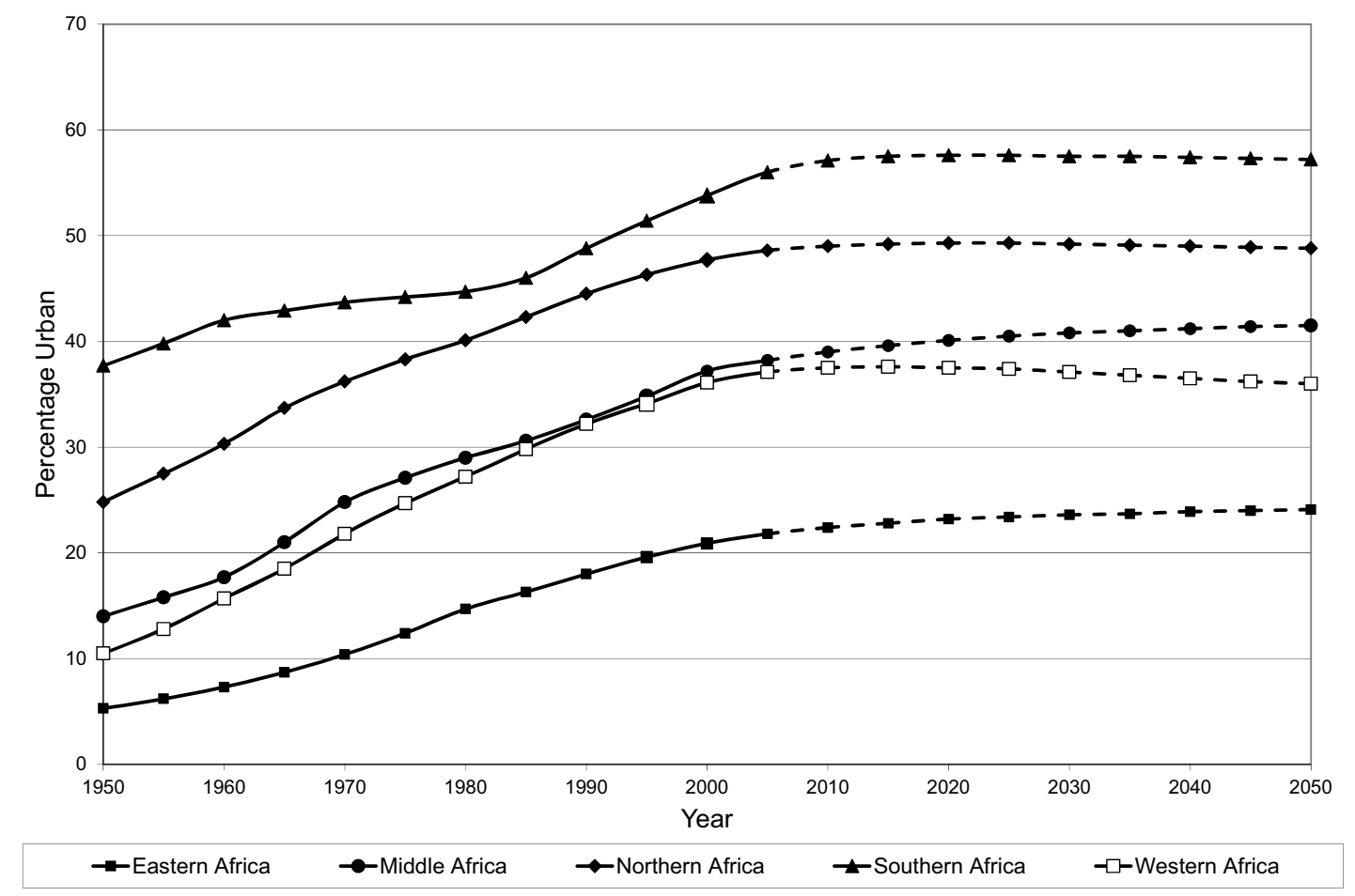

Figure 13 Urban Trends (1950-2005) and Projections (2005-2050) by African sub-Regions (Western Africa without Nigeria, Burkina Faso, Côte d'Ivoire, and Mali; Eastern Africa without Eritrea)

Figure 13 also shows that our projected urbanization trends do not change the hierarchy just described. Actually the percentage urban does not differ much from the 2005 estimates, except for Middle Africa (where it would be 5 points higher) and for Western Africa (where it be would slightly lower). Not surprisingly, Southern and Northern African countries, many of which being at intermediate-level in economic terms, are the most urbanized. Eastern Africa still lags far behind, staying below $25 \%$ urban. 
In Eastern Africa, there is a clear distinction between least urbanized countries on one side (Burundi, Ethiopia, Kenya, Malawi, Rwanda, Uganda) where the percentage urban range from $10 \%$ to $20 \%$ in 2000 and will stay below $20 \%$ in 2050, and more urbanized countries (Tanzania, Zambia, Zimbabwe) to which we should add a number of islands of the Indian ocean as well as small countries (Comoros, Madagascar, Mauritius, Seychelles, Somalia), where the percentage urban varies between $22 \%$ and $43 \%$ in 2000 and will probably range between $29 \%$ and $50 \%$ in 2050. Dibouti and the Reunion Island are two exceptions, with percentage urban respectively $76 \%$ and $90 \%$ in 2000 with a slight increase to $77 \%$ and $92 \%$ foreseen in 2050 . Eastern Africa illustrates well the importance of ports (i.e. access to maritime commercial routes) in urbanization: coastal countries and islands are usually more urbanized, all things being equal.

In Middle Africa, four countries had a fairly high percentage of urban population in urban areas (from 49\% to $58 \%$ ) in 2000: Angola, Cameroon, Congo and Sao Tome \& Principe. Two countries were fairly urbanized, Central African Republic (38\%) and Equatorial Guinea (39\%), while Chad (23\%) and Democratic Republic of Congo (30\%) were the least urbanized in 2000. The exception is Gabon (80\% in 2000). Our projections do not make these percentages vary much for 2050 except for Cameroon (80\%) and Gabon (95\%). Gabon illustrates the role of tropical and rain forests in constraining population growth in urban areas. For equal level of development, countries with large ports seem to be more urbanized.
In Northern Africa, the most urbanized countries in 2000 were Morocco, Algeria, Tunisia, Libya (53\% to $76 \%$ ) and Western Sahara (84\%), as opposed to Sudan and Egypt (33\% and 43\%). Our projections add up to a maximum of 6 percentage points to these figures, with the exception of Tunisia (increase from $63 \%$ to $73 \%$ ). In Southern Africa, there is clear divide between South Africa (57\%) and Botswana (53\%) on one side, and Lesotho (20\%), Swaziland (23\%) and Namibia (32\%) on the other side. Again our projections for 2050 do not change much these percentages. To note, South Africa by far the most populous countries of the region, with $62 \%$ urban population in 2050 , is lifting the percentage urban of Southern Africa from 54\% in 2000 to $57 \%$ in 2050. In Northern and Southern Africa, we have examples of fairly large countries (in population and in superficies) that range at the intermediate level in terms of economic development, with around $60 \%$ of their population living in urban areas.

Lastly, urbanization in Western Africa appears to be fairly homogenous with most rates varying between $28 \%$ and $44 \%$ in 2000 , with two low exceptions, Niger (16\%) and Burkina Faso (18\%), and two high exceptions Gambia (49\%) and Cape Verde (53\%). Projections to 2050 would keep most of these rates in the same range except for Gambia (from $49 \%$ to $72 \%$ ) and Togo (37\% to 49\%). Despite the uncertainties of our projections on Burkina Faso, Côte d'lvoire, Mali and Nigeria, we can make the reasonable assumption that their urbanization will not change much before 2050 , considering that it did not change much either 
for other countries in Western Africa and in Africa in general. Therefore the estimate for the whole of Western Africa would remain below $40 \%$ for 2050 , a level comparable to that of 2000.

In our model, the countries predicted to have the highest percentage of its population living in urban areas by 2050 , will be the Reunion Island (92\%, while the UN predicts 97\%) and
Gabon (95\%, while the UN predicts $94 \%)$. Gabon is the only country in Africa where the 3rd order polynomial model predicts a higher percentage of urban percentage of the population by 2050 than the UN. Among African countries predicted with lowest percentage urban are all in Eastern Africa and include Uganda (12\%), Burundi (I5\%), Malawi (I7\%), Rwanda (I7\%), and Ethiopia (18\%).

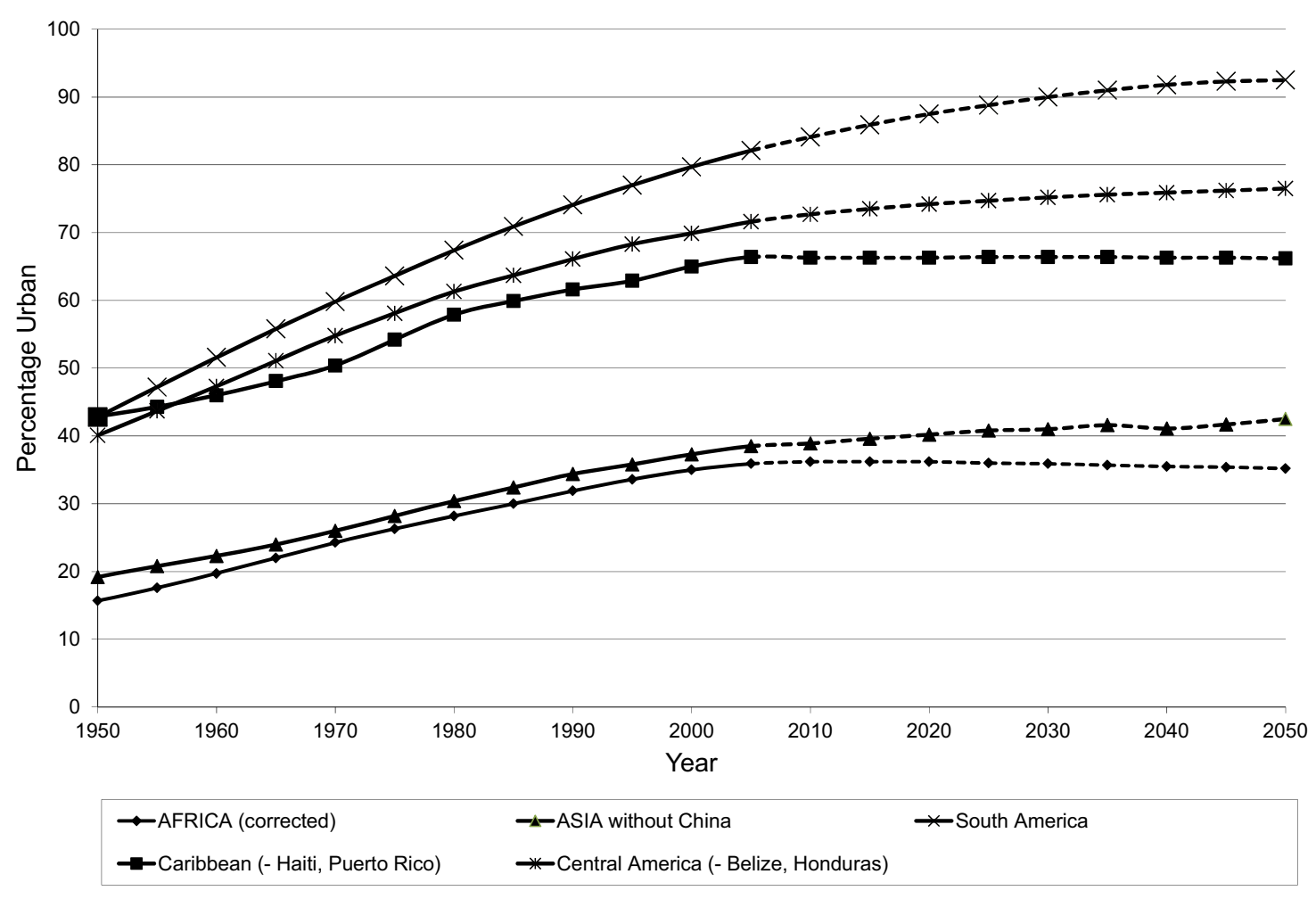

Figure I4 Urban Trends (1950-2005) and Projections (2005-2050) by Developing subRegions (Africa without Nigeria, Burkina Faso, Côte d'Ivoire, Mali and Eritrea)

Extending the estimate to the whole of Africa, which percentage urban over the 2000-2050 would stay virtually stable, slightly above $35 \%$, excluding countries lacking consistent trends. With these countries included the percentage would probably not exceed $37 \%$. Compared to other developing parts of the world (Figure 14), Africa would remain one of the least urbanized continents of the world, only matched by Asia (without China). This is in sharp contrast with the UN projections $(62 \%$ for all countries, $59 \%$ without the countries that we excluded for lack of consistent trends). The high urbanisation in Latin America can be partly explained by physical constraints 
of the Caribbean and countries along the Andes as population of islands and mountainous countries tend to concentrate more in cities. However, these physical constraints do not operate in highly urbanised Central America, although its level of development is comparable to the rest of Latin America. The level of urbanisation of Latin America actually reflects its higher rank in the world economy than Africa and Asia.

\section{Conclusion}

To summarize our findings, Eastern Africa region has the lowest proportion of population living in urban areas, and only $24 \%$ of the population would be leaving in urban areas by 2050 according to our projections, against $47 \%$ according to the UN. The model foresees that Southern Africa will have the highest percentage of population living in urban areas by 2050, essentially because South Africa is weighing heavily in the region. The model predicts that $57 \%$ of Southern Africa region population (62\% in South Africa) will be living in urban areas while the UN predicts $77 \%$. Northern Africa comes next to Southern Africa in our projections (49\%) while the UN foresees $71 \%$ of population living in urban areas. The UN model projects that $68 \%$ and $77 \%$ of the population respectively in Middle Africa and Western Africa will be living in urban areas while our model foresees respectively $42 \%$ and below $40 \%$. For Africa as a whole, the percentage urban will probably hovers in the future around the same level as currently observed, i.e. around $37 \%$, contrary to the UN-projected $62 \%$ in 2050 . In other words, the urban proportion will not vary significantly from 2000 to 2050 according to our projection model.

If these findings were to be confirmed in the future, it would mean than the urban transition in Africa is already over, except in a few, generally small countries. This goes counter to the conventional wisdom that urban population grows faster than total population growth in Africa, independently of the progress in economic and social development. Our projections are based on historical trends at country level and do not make an assumption of convergence toward the high level of urbanization observed in developed countries, as the UN model does. Consequently the resulting projected picture is that of a very unequal urban world were Africa remains predominantly rural, after a fast but short period of urban transition.

Our projections, if they were to be confirmed, would have population policy implications. First, since urban areas in Africa are now growing out of natural increase rather from positive net migration (Chen et al., 1998), urban growth in the coming years can only be controlled through reproductive health programmes and not through limitation of rural-to-urban migration. Second, even if the current levels of urban growth seem to exceed the capacity of African cities to absorb more population, the declining urban growth is disturbing from the economic development point of view. Urbanization is strongly associated with economic development. Stabilisation of the proportion of urban population slightly over the current level, i.e. well below $50 \%$, is synonymous with persistent economic marginalisation of Africa in the world 
economy, to the exception of South Africa and North African countries, which economies are emerging. This underlines the inequalities within Africa and the leading role that countries at the extreme North and South of the continent can play to integrate the rest of the continent in the global economy. These countries attract already a number of international migrants from other parts of the continent attracted by the relative stability and prosperity of these intermediate-level countries, sometimes hoping to transit to more developed countries. Within-Africa economic migrations became a major population policy issue that will need special attention in the future, and more so when these migrations are also associated with political instability. Stabilisation below $50 \%$ urban also underlines inequalities within each country between rural and urban areas, but also within urban areas and within cities. The third policy implication is that of reducing these inequalities. The 'urban penalty' (the excess mortality in poor urban areas) that was thought to belong to the European $19^{\text {th }}$ century (Gould, 1998), is now revived in African cities slums (Zulu et al., 20II). Population and health policies directed at the poorest and often very mobile urban slum population need to be designed. To sum up, declining urban growth and stabilisation of urbanization at relatively low level as compared to the rest of the world has implications for all components of the population dynamics: mortality, fertility and migration.

\section{Acknowledgement}

Our thanks go to the United Nations Department of Economic and Social
Affairs - Population Division for providing the data. We benefited from the comments made on an earlier version of the paper presented at the fourth Congress of the Latin American Population Association (AsociacionLatinoamericana de Poblacion - ALAP), in La Habana Cuba.

\section{References}

AFRICAPOLIS TEAM 20II. Urbanization trends 1950-2020: a geo-statistical approach. West Africa. Fact Sheets by Country. Paris: AFD-SEDET.

BOCQUIER, P. 2005. World Urbanization Prospects: an alternative to the UN model of projection compatible with urban transition theory. Demographic Research, 12, 197-236.

CHEN, N., VALENTE, P. \& ZLOTNIK, H. 1998. What Do We Know about Recent Trends in Urbanization. In: BILSBORROW, R. E. (ed.) Migration, Urbanization, and Development: New Directions and Issues. USA: United Nations Population Fund (UNFPA) and Kluwer Academic Publishers.

COHEN, B. 2004. Urban Growth in Developing Countries: A Review of Current Trends and a Caution Regarding Existing Forecasts. World Development, 32, 23-5I.

DYSON, T. 2011. The Role of the Demographic Transition in the Process of Urbanization. Population and Development Review, 37, 34-54.

GOULD, W. T. S. 1998. African mortality and the new 'urban penalty'. Health and Place, 4, I7II8I.

HUGO, G. \& CHAMPION, A. 2003. New Forms of Urbanisation, 
Aldershot, Ashgate.

KESSIDES, C. 2005. The Urban Transition in Sub-Saharan Africa: Implications for Economic Growth and Poverty Reduction. World Bank Africa Region - Working Paper Series, 116.

LUCASSEN, J. \& LUCASSEN, L. 2009. The mobility transition revisited, 1500-1900: what the case of Europe can offer to global history. Journal of Global History, 2009, 347377.

MUKANDILA, A. 2010. The Dynamics of Urban Population Developments: Projection Model of Urban-Growth Differences. Masters of Arts Dissertation, University of the Witwatersrand.

NATIONAL RESEARCH COUNCIL (ed.) 2003. Cities Transformed Demographic Change and Its Implications in the Developing World, Washington D.C.: The National Academies Press.

O'NEILL, B. C. \& SCHERBOV, S. 2006. Interpreting UN Urbanization Projections Using a Multi-state Model. Laxenburg, Austria: IIASA.

POTTS, D. 2012. Challenging the myths of urban dynamics in subSaharan Africa: the evidence from Nigeria World Development, (to be published).

REHER, D. S. 20II. Economic and Social Implications of the Demographic Transition. Population and Development Review, 37, I I-33.

SATTERTHWAITE, D. 2007. The transition to a predominantly urban world and its underpinnings. Human Settlements Discussion Paper Series Urban Change, 91.

SKELDON, R. 1997. Migration and Development: A Global Perspective, London, Longman.

UN-HABITAT 2007. Enhancing Urban Safety and Security - Global Report on Human Settlements. Nairobi: UN-Habitat.

UN-HABITAT 2008. The State of African Cities 2008 - A framework for addressing urban challenges in Africa, Nairobi, UN-Habitat.

UNFPA 2007. Unleashing the Potential of Urban Growth, New York, United Nations Population Fund.

UNITED NATIONS 2009. World Urbanization Prospects: The 2008 Revision. Data Tables and Highlights. New York: United Nations, Department of Economic and Social Affairs, Population Division.

WORLDWATCH INSTITUTE (ed.) 2007. State of the World 2007: Our Urban Future, Washington, DC: Earthscan.

ZELINSKY, W. 197I. The hypothesis of the mobility transition. The Geographical Review, 6I, 219-249.

ZULU, E., BEGUY, D., EZEH, A., BOCQUIER, P., MADISE, N., CLELAND, J. \& FALKINGHAM, J. 20II. Overview of migration, poverty and health dynamics in Nairobi City's slum settlements. Journal of Urban Health, 88, I85-199. 


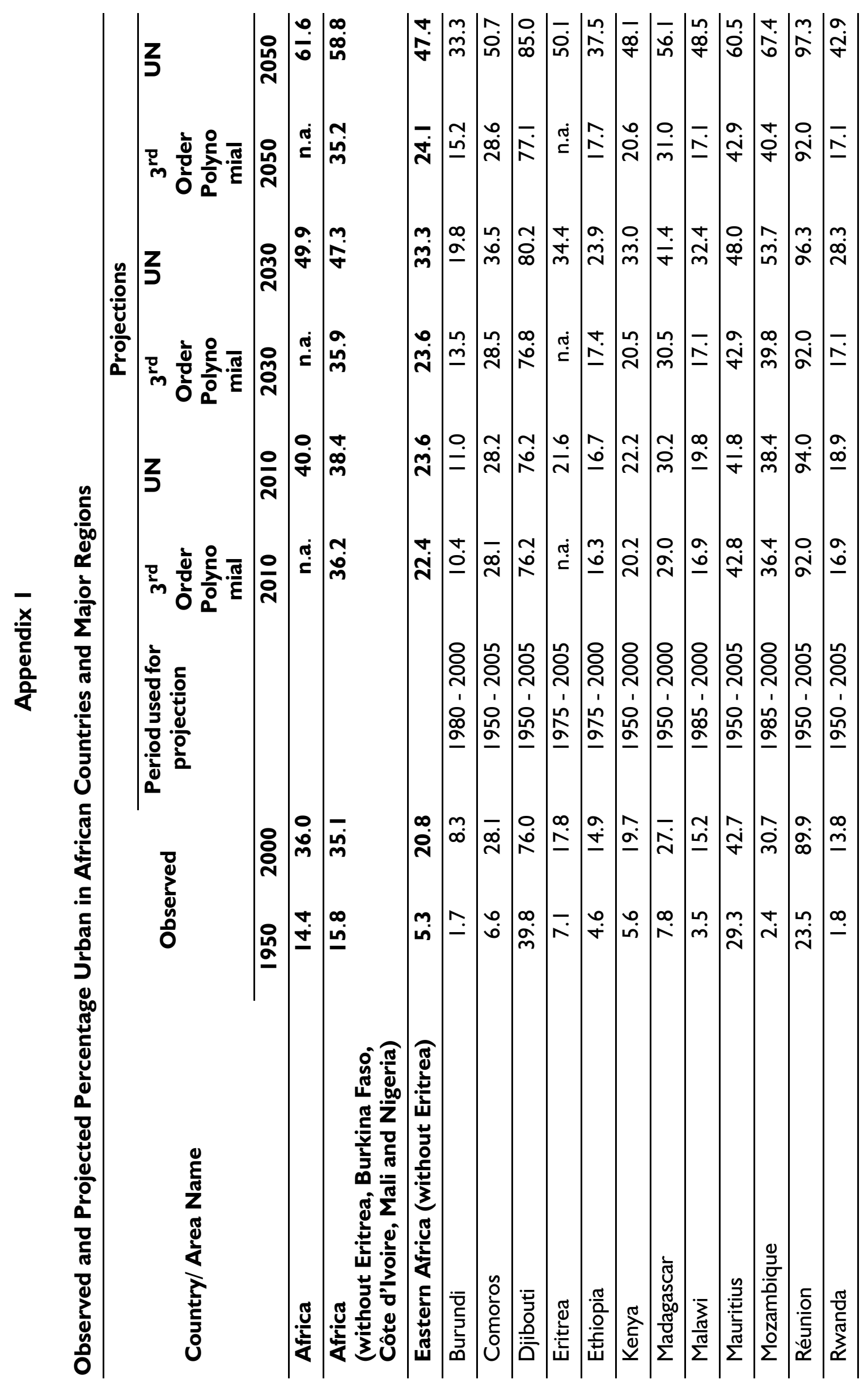




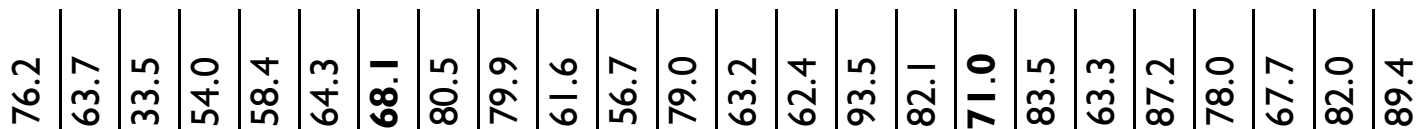
$\infty$ t

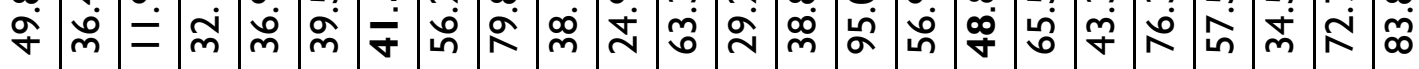

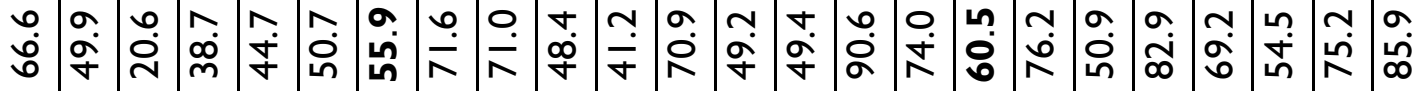

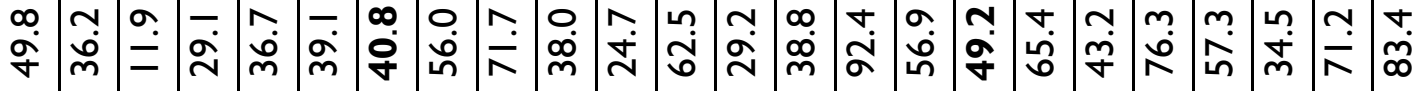

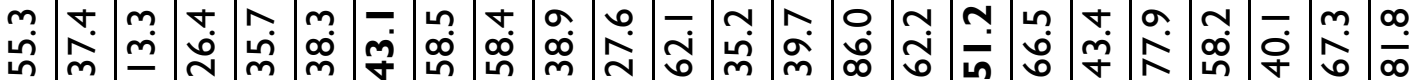

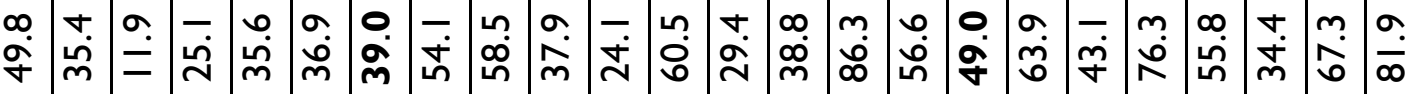

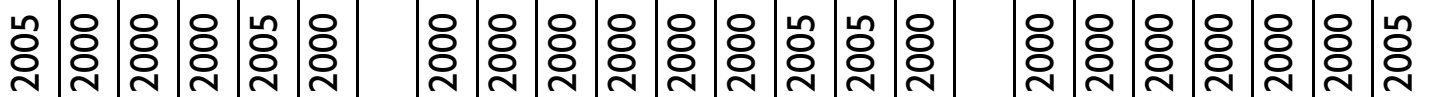
占

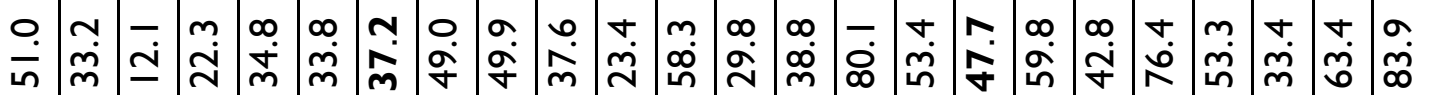

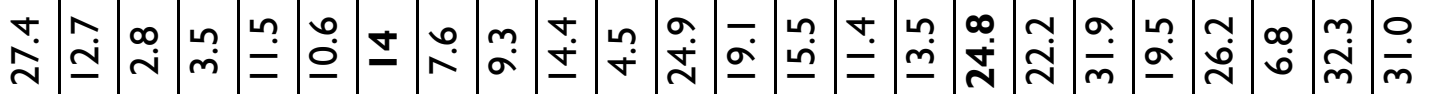

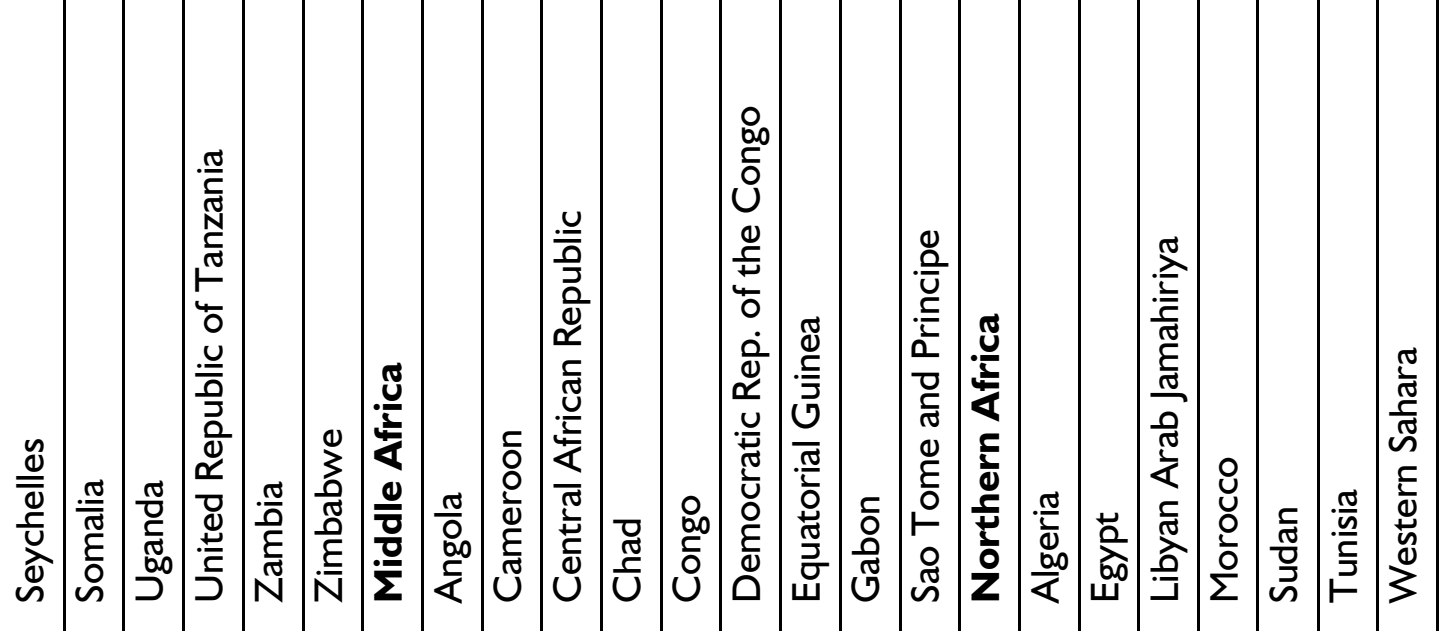




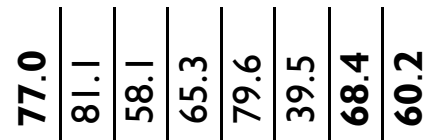

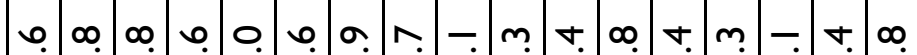

๑ ஷ

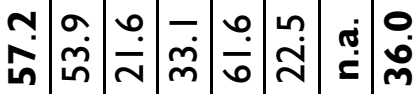

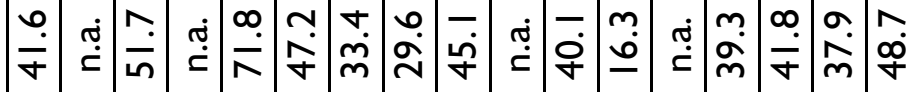

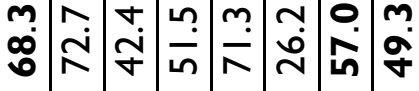

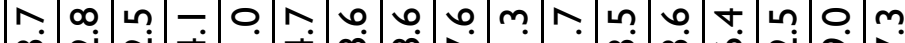

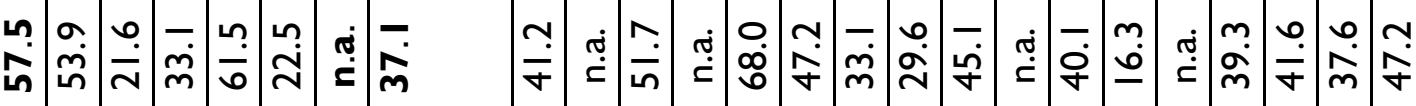

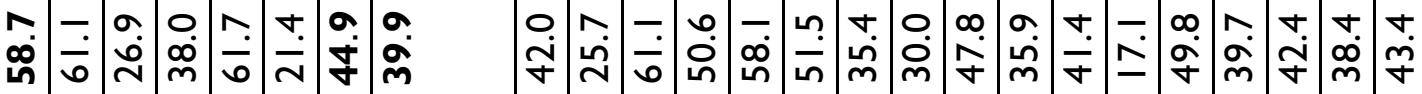

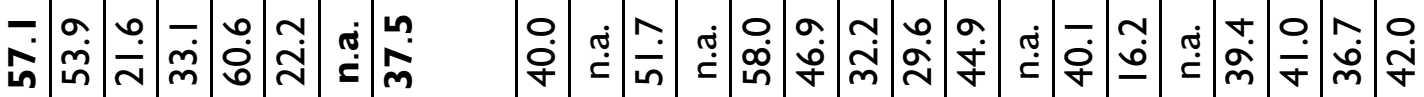

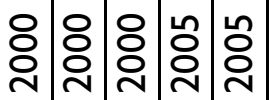

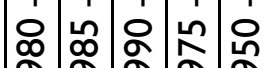

$\underline{-\sigma} \underline{\sigma} \underline{-}$

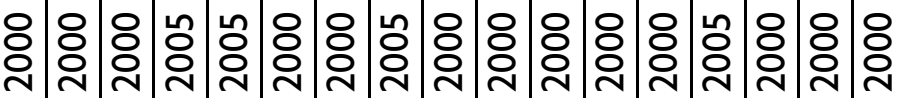

융

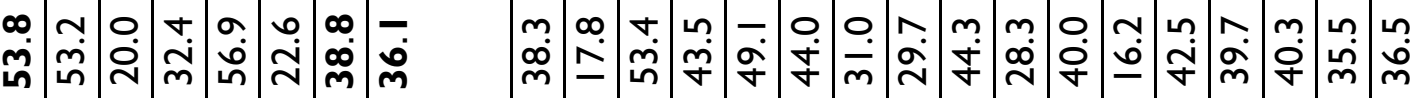

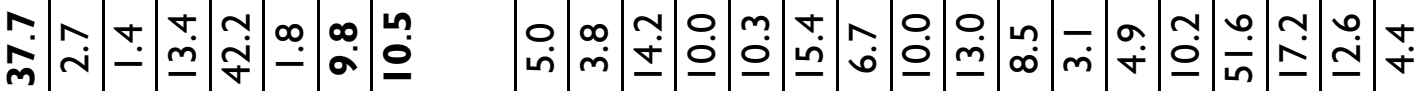

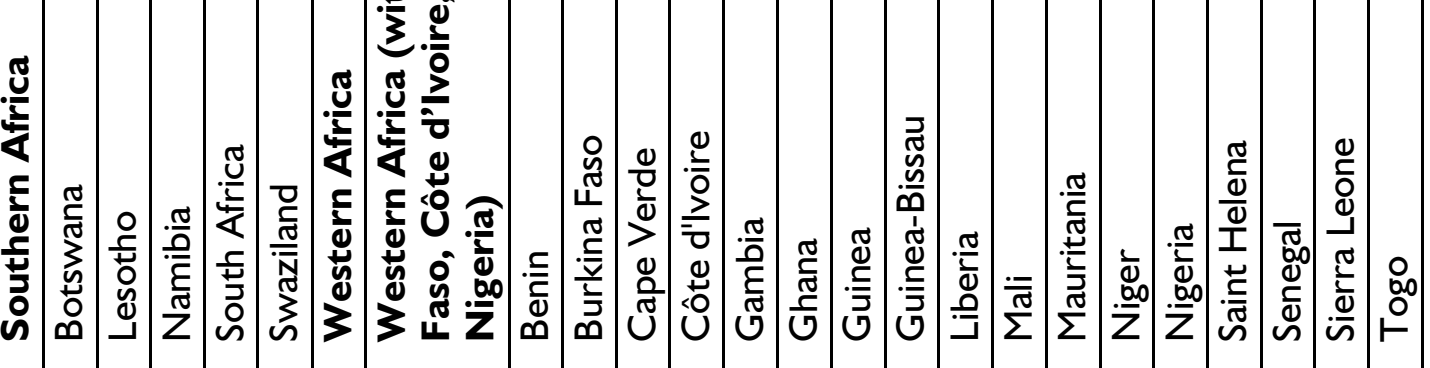




\section{APPENDIX 2}

Distribution of countries according to the quality of the goodness of fit and the stage in the urban transition

\begin{tabular}{|c|c|c|c|c|c|}
\hline \multirow{2}{*}{$\begin{array}{l}\text { Stage of the } \\
\text { transition }\end{array}$} & \multicolumn{5}{|c|}{ Goodness of fit } \\
\hline & Excellent & Good & Average & Poor & Unacceptable \\
\hline \multirow{13}{*}{$\begin{array}{l}\text { Early to mid- } \\
\text { stage }\end{array}$} & Angola & Burundi & Benin & Algeria & Burkina Faso \\
\hline & & Gambia & Botswana & Cameroon & Eritrea \\
\hline & & Madagascar & Congo & Chad & Mali \\
\hline & & Morocco & Gabon & Ghana & Nigeria \\
\hline & & Mozambique & Kenya & Guinea & Sao Tome \& Pr. \\
\hline & & Zimbabwe & Malawi & Lesotho & Tanzania \\
\hline & & & Sudan & Namibia & \\
\hline & & & Tunisia & Réunion & \\
\hline & & & & Rwanda & \\
\hline & & & & Somalia & \\
\hline & & & & South Africa & \\
\hline & & & & Togo & \\
\hline & & & & Zambia & \\
\hline \multirow[t]{8}{*}{ Late stage } & & Djibouti & Central Africa & Cape Verde & Côte d'Ivoire \\
\hline & & Ethiopia & Comoros & Gambia & DRC \\
\hline & & Liberia & Egypt & Guinea Bissau & Saint Helena \\
\hline & & Lybia & Eq. Guinea & Niger & \\
\hline & & Mauritius & Mauritania & Seychelles & \\
\hline & & & Senegal & Swaziland & \\
\hline & & & Sierra Leone & Uganda & \\
\hline & & & Zambia & $\begin{array}{l}\text { Western } \\
\text { Sahara }\end{array}$ & \\
\hline
\end{tabular}

